Article

\title{
VHL, BAP1, PBRM1, SETD2 expression in clear cell renal car- cinoma, association with PD-1, PD-L1, PD-L2 mRNA level
}

\author{
Liudmila Spirina ${ }^{1,2, *}$, Zahar Yurnazov ${ }^{1}$, Evgeny Usynin ${ }^{1}$ Firstname ${ }^{1}$, Irina Kondakova ${ }^{1}$, Ekaterine Ladutko ${ }^{2}$ \\ and Evgeny Choynzonov 1,2 \\ 1 Cancer Research Institute, Tomsk National Research Medical Center; Russia, info@oncology.tomsk.ru \\ 2 Siberian State Medical University; Tomsk, Russia, rector@ssmu.ru \\ * Correspondence: spirinalvl@mail.ru; Tel.: +79609758577
}

\begin{abstract}
Novel mechanism of ccRCC progression is essential, including PBRM1, BAP1, and SETD2 in histone-modifying and chromatin remodeling genes. The study aimed to investigate VHL, PD-1, PD-L1, PD-L2. BAP1, PBRM1, SETD2 expression in ccRCC primary cancers and metastatic tissues associated with the cancer dissemination. A total of 62 patients with RCC were enrolled in the study. Investigation of mRNA level of VHL, PD-1, PD-L1, PD-L2. PCR in realtime performed BAP1, PBRM1, SETD2 with the previous RNA isolation. Western Blotting analysis was used for detecting the p-VHL protein content in tissues. The VHL expression and pVHL content determined the aggressive cancer behavior and elevated in disseminated tumors. The cancer dissemination was accompanied by an increase in both mRNA and VHL content. The PD-L2 prevalence in metastatic cancers is crucial in tumor progression. ccRCC progression in VHL overexpression is associated with the decrease in BAP1 gene expression. It is revealed the heterogeneity in molecular markers in primary tumors and metastases. The low mRNA level of BAP1, PBRM1, SETD2, PD-1, PD-L1, PD-L2 in metastases compared with primary tumors were found. We show a novel mechanism for VHL tumor progression and present a new instrument and factor targeting tumor-related pathologies with $\mathrm{p}$-VHL/HIF altered function.
\end{abstract}

Keywords: kidney cancers; VHL; PD-1; PD-L1; PD-L2; BAP1; PBRM; SETD2; primary tumor; metastasis.

\section{Introduction}

VHL is mutated in most patients with clear cell renal cell carcinoma (ccRCC), with conflicting clinical relevance. Recent studies have identified recurrent mutations in histone-modifying and chromatin remodeling genes, including BAP1, PBRM1, and SETD2. Current evidence suggests that BAP1 mutations are associated with aggressive disease [1]. The von Hippel-Lindau gene (VHL) product acts as the substrate-recognition component of an E3 ubiquitin ligase complex that ubiquitylates the catalytic alpha subunit of hypoxia-inducible factor (HIF) for oxygen-dependent destruction. Somatic mutations or loss of von Hippel-Lindau (pVHL) happen in most VHL disease tumors, which present a constitutively active Hypoxia Inducible Factor (HIF), essential for tumor growth [2].

A decrease in pVHL expression from the adjacent healthy tissues to the tumor's ones was found in recent studies [3]. But the content of pVHL in ccRCC primary tumors and metastatic sites remains unknown. There are current data repost the presence of VHL mutations is not concordant with mRNA or protein expression. Nonsense mutations of the VHL gene appear to be related to poorer prognosis and survival [2]. Multiple molecular targets have been developed based on blocking major 
signaling pathways directly or indirectly involved in ccRCC tumor progression, metastasis, angiogenesis, and survival [4].

Inactivation of the VHL gene is an early event in ccRCC carcinogenesis [5]. The pVHL targets could be regulated independently of VHL mutation (and possibly by hypoxia alone); this data suggests that other pVHL marks may be more crucial in renal carcinogenesis [6]. VHL loss in clear-cell renal cell carcinoma (RCC) leads to increased levels of hypoxia-inducible factors (HIF) and overexpression of HIF target genes, such as VEGF and others. VEGF-targeted agents are standard in advanced clear-cell RCC, but biomarkers of activity are lacking. Several potential biomarkers along the VHL/HIF-1 $\alpha / \mathrm{HIF}-2 \alpha$ axis were not predictive for targeted therapy in patients with advanced clear-cell RCC. Additional efforts must continue to identify biomarkers associated with clinical outcomes to VEGF-targeted agents in metastatic RCC [7].

Several novel recurrent mutations of histone-modifying and chromatin remodeling genes have been identified in renal cell carcinoma. These mutations cause loss of function of several genes located close to VHL and include PBRM1, BAP1, and SETD2. Chromosome 3p harbors BRCA1-associated protein-1 (BAP1) [8]. PBRM1 encodes for BAF180, a component of the SWI/SNF chromatin remodeling complex, and is inactivated in, on average, $36 \%$ of clear cell renal cell carcinoma (ccRCC).

Mutations of BAP1 encode for the histone deubiquitinase BRCA1 associated protein- 1 and are present in $10 \%$ of RCCs. They are essentially mutually exclusive with PBRM1 mutations. Mutations to SETD2, a histone methyltransferase, occur in $10 \%$ of cCRCC. BAP1- or SETD2-mutated ccRCCs have been associated with poor overall survival, while PBRM1 mutations seem to identify a favorable group of ccRCC tumors [9]. It is found PRBM-1 loss is associated with more aggressive mccRCC and could be therapeutic targets for anti-cancer therapy [10].

The relationship between gene mutation, loss of protein expression, and the correlations with clinicopathological parameters is essential for understanding renal cancer progression. The combined functional inactivation of PBRM1, BAP1, SETD2, and pVHL is critical for ccRCC advancement [11]

Tumor immunogenicity is one of the urgent problems in modern oncology. Receptor PD-1 - (Programmed cell death 1; CD279) plays a role in the cellular differentiation of immune cells [12]. Under physiological conditions, when PD-1 interacts with its ligands (PD-L1 PD-L2), an inhibitory signal is transmitted that prevents the development of an excessive immune response, triggering the processes of apoptosis of cytotoxic lymphocytes [13].

The recent analysis highlights the VHL impact on the biological processes, including metabolism, immune regulation, apoptosis, and cell movement. Its overexpression promotes immune system activation and sensitivity to interferon therapy [14]. Recent studies showed that PD-L1 expression levels positively correlate with VHL mutation and HIF-2 $\alpha$ expression. VHL mutations positively correlate with PD-L1 expression in ccRCC and may influence the response to ccRCC anti-PD-L1/PD1 immunotherapy [15].

In the presented works, the relationship of the positive expression of PD-L1 with the sporadic and hereditary ccRCC aggressiveness is currently noted [16]. It was revealed an association between the VHL biallelic inactivation and the PD-L1 increased expression [15]. In addition, there is evidence if protein E3 of ubiquitin ligase is functional, an increase in the PD-L1 / PD-1 will be observed [17]. Unlike PDL1, PD-L2 has a less pronounced association with disease prognosis [18].

Currently, the prognostic role of the PD-L1 level with the cancer aggressiveness and the unfavorable outcome development is prominent [19]. Its function is currently not clearly defined. However, blocking antitumor immunity and inhibition of cytotoxic T cells and NK cells is possible, among other things, by increasing the 
expression of PD-L2 [20]. However, there is evidence of a greater affinity of this ligand for PD-1 receptors of immunocompetent cells [21]. It is known that the expression of PD-1, PD-L1, and PD-L2 differs in primary tumor tissues and metastases [22].

The changes in AKT/mTOR and MAPK signaling cascades in the ccRCC can influence tumorigenesis [23-24]. In addition, the expression of $\mathrm{p}-\mathrm{AKT}$ is closely associated with the expression of ligands PD-L1, PD-L2 in tumor cells [25]. It is known that tumor withdrawal from immune surveillance occurs due to the production of ligands PD-L1 PD-L2 by tumor cells, which is associated with the development of hypoxia and the level of the HIF-1 protein [26-27]. In particular, for kidney cancer, an association of PD-L1 expression with a high level of HIF-2 $\alpha$ by the presence of lymphocytic infiltration has been shown [28]. The study aimed to investigate VHL, PD-L1, PD-L2. BAP1, PBRM1, SETD2 expression in ccRCC primary cancers and metastatic tissues associated with the cancer dissemination.

\section{Results}

2.1. VHL, PD, PD-L1, PD-L2. BAP1, SEDT1, PRBM distribution in ccRCC tumor size growth and dissemination.

ccRCC begins with an intragenic mutation in the von Hippel-Lindau (VHL) gene and loss of $3 p$ (where VHL is located). But several studies revealed the presence of other abnormalities. We tried to found the association of VHL, PD, PD-L1, PD-L2. BAP1, SEDT1, PRBM with clinical signs of the disease.

Table 1. Distribution of increased and decreased gene's expression in ccRCC depended on the tumor size

\begin{tabular}{|c|c|c|c|c|c|}
\hline \multirow{2}{*}{\multicolumn{2}{|c|}{$\begin{array}{l}\text { Expression, } \\
\text { Relative Units }\end{array}$}} & \multicolumn{3}{|c|}{ Tumor size } & \multirow{2}{*}{$\begin{array}{l}\chi^{2-} \\
\text { distribution }\end{array}$} \\
\hline & & \multirow{2}{*}{$\frac{\mathbf{T}_{1} \mathbf{N}_{0} \mathbf{M}_{0}}{7(77.78)}$} & \multirow{2}{*}{$\frac{\mathbf{T}_{2} \mathbf{N}_{0} \mathbf{M}_{0-1}}{9(52.94)}$} & \multirow{2}{*}{$\frac{\mathbf{T}_{3} \mathbf{N}_{0} \mathbf{M}_{1}}{6(85.71)}$} & \\
\hline VHL, & $>1.0$ & & & & $\chi^{2-29.25}$ \\
\hline$(\mathrm{n}, \%)$ & $<1.0$ & $2(22.22)$ & $8(47.06)$ & $1(14.29)$ & $\mathrm{p}=0.0001$ \\
\hline \multirow{2}{*}{$\begin{array}{l}\mathrm{PD}, \\
(\mathrm{n}, \%)\end{array}$} & $>1.0$ & $9(100.00)$ & $7(41.18)$ & $3(43.86)$ & \multirow{2}{*}{$\begin{array}{l}\chi 2-95.07 \\
p<0.0001\end{array}$} \\
\hline & $<1.0$ & $0(0.00)$ & $10(58.82)$ & $4(57.14)$ & \\
\hline \multirow{2}{*}{$\begin{array}{l}\text { PD-L1, } \\
(\mathrm{n}, \%)\end{array}$} & $>1.0$ & $5(55.56)$ & $9(52.94)$ & $1(14.29)$ & \multirow{2}{*}{$\begin{array}{l}\chi 2-44.37 \\
p<0.0001\end{array}$} \\
\hline & $<1.0$ & $4(44.44)$ & $8(47.06)$ & $6(85.71)$ & \\
\hline \multirow{2}{*}{$\begin{array}{l}\text { PD- L2, } \\
(\mathrm{n}, \%)\end{array}$} & $>1.0$ & $8(88.89)$ & $12(70.59)$ & $4(57.14)$ & \multirow{2}{*}{$\begin{array}{l}\chi 2-25.42 \\
p<0,0001\end{array}$} \\
\hline & $<1.0$ & $1(11.11)$ & $5(29.41)$ & $3(42.86)$ & \\
\hline \multirow{2}{*}{$\begin{array}{l}\text { BAP, } \\
(n, \%)\end{array}$} & $>1.0$ & 7 (77.78) & 7 (38.89) & $3(42.86)$ & \multirow{2}{*}{$\begin{array}{l}\chi 2-36.91 \\
\mathrm{p}<0.0001\end{array}$} \\
\hline & $<1.0$ & $2(22.22)$ & $11(61.11)$ & $4(57.14)$ & \\
\hline \multirow{2}{*}{$\begin{array}{l}\text { SET1, } \\
(\mathrm{n}, \%) \\
\end{array}$} & $>1.0$ & $4(44.44)$ & $9(50.00)$ & $3(42.86)$ & \multirow{2}{*}{$\begin{array}{l}\chi 2-1.14 \\
p=0.5655\end{array}$} \\
\hline & $<1.0$ & $5(55.56)$ & $9(50.00)$ & $4(57.14)$ & \\
\hline $\begin{array}{l}\text { PRBM, } \\
(\mathrm{n}, \%)\end{array}$ & $>1.0$ & $7(77.78)$ & $7(38.89)$ & $3(42.86)$ & $\begin{array}{l}\chi 2-36.91 \\
p<0.0001\end{array}$ \\
\hline
\end{tabular}

We found the association of VHL increased expression ( $>1.0$ Relative Units) in $\mathrm{T}_{3} \mathrm{~N}_{0} \mathrm{M}_{1}$ stage and in disseminated cancers (Table 1 and 2 ). Up to 85.71 with $\mathrm{T}_{3} \mathrm{~N}_{0} \mathrm{M}_{1}$ and, $80 \%$ of patients with disseminated ccRCC had high mRNA levels of VHL. At the same time, the prevalence of decreased levels of BAP1, PRBM, PD-1, PD-L1, PD-L2 was revealed in metastatic ccRCC. The revealed data verify the majority of VHL gene abnormalities in ccRCC. 
Table 2. Distribution of increased and decreased gene's expression in ccRCC depended on cancer dissemination

\begin{tabular}{|c|c|c|c|c|}
\hline \multirow{2}{*}{\multicolumn{2}{|c|}{$\begin{array}{c}\text { Expression, } \\
\text { Relative Units }\end{array}$}} & \multicolumn{2}{|c|}{ Cancer spreading } & \multirow{4}{*}{$\begin{array}{l}\chi 2 \text {-distribution } \\
\chi 2-50.47 \\
\mathrm{p}=0.0001\end{array}$} \\
\hline & & \multirow{2}{*}{$\frac{\text { localized ccRCC }}{6(40.00)}$} & \multirow{2}{*}{$\begin{array}{c}\text { metastatic } \\
\text { ccRCC } \\
16(88.89)\end{array}$} & \\
\hline VHL & $>1.0$ & & & \\
\hline$(n, \%)$ & $<1.0$ & $9(60.00)$ & $2(11.11)$ & \\
\hline \multirow{2}{*}{$\begin{array}{c}\mathrm{PD},(\mathrm{n}, \\
\%)\end{array}$} & $>1.0$ & $12(80.00)$ & $7(38.89)$ & \multirow{2}{*}{$\begin{array}{l}\chi^{2-33.66} \\
\mathrm{p}=0.0001\end{array}$} \\
\hline & $<1.0$ & $3(20.00)$ & $11(38.89)$ & \\
\hline \multirow{2}{*}{$\begin{array}{c}\text { PD-L1, } \\
(\mathrm{n}, \%)\end{array}$} & $>1.0$ & $10(66.67)$ & $5(27.78)$ & \multirow{2}{*}{$\begin{array}{l}\chi^{2-29.09} \\
p=0.0001\end{array}$} \\
\hline & $<1.0$ & $5(33.33)$ & $13(72.22)$ & \\
\hline \multirow{2}{*}{$\begin{array}{c}\text { PD- L2, } \\
(\mathrm{n}, \%)\end{array}$} & $>1.0$ & $13(86.67)$ & $11(61.11)$ & \multirow{2}{*}{$\begin{array}{l}\chi^{2-15.78} \\
\mathrm{p}=0.0001\end{array}$} \\
\hline & $<1.0$ & $2(13.33)$ & $7(38.89)$ & \\
\hline \multirow{2}{*}{$\begin{array}{c}\mathrm{BAP},(\mathrm{n}, \\
\%)\end{array}$} & $>1.0$ & $11(68.75)$ & $6(33.33)$ & \multirow{2}{*}{$\begin{array}{l}\chi^{2-23.95} \\
\mathrm{p}=0.0001\end{array}$} \\
\hline & $<1.0$ & $5(31.25)$ & $12(66.67)$ & \\
\hline \multirow{2}{*}{$\begin{array}{l}\text { SET1, } \\
(n, \%)\end{array}$} & $>1.0$ & $8(50.00)$ & $8(44.44)$ & \multirow{2}{*}{$\begin{array}{l}\chi 2-0.42 \\
p=0.5169\end{array}$} \\
\hline & $<1.0$ & $8(50.00)$ & $10(55.56)$ & \\
\hline $\begin{array}{c}\text { PRBM, } \\
(\mathrm{n}, \%)\end{array}$ & $>1.0$ & $11(68.75)$ & $8(44.44)$ & $\begin{array}{l}\chi^{2-11.18} \\
\mathrm{p}=0.0008\end{array}$ \\
\hline
\end{tabular}

\subsection{VHL expression and $p$-VHL content increase in metastatic ccRCC.}

All figures and tables should be cited in the main text as Figure 1, Table 1, etc. The expression and content of VHL depended on the stage of the disease (criterion T) and the extent of the tumor process in ccRCC. The VHL expression was increased by 12.5 times in patients with a $\mathrm{T}_{3-4} \mathrm{~N}_{0-1} \mathrm{M}_{1}$ stage than $\mathrm{T}_{1-2} \mathrm{~N}_{0} \mathrm{M}_{0}$. The found change was accompanied by a 5-fold decrease in the p-VHL content (Figure 1). The most significant changes were revealed when studying the prevalence of the tumor process. Substantial changes in the expression and protein level under study were observed in the metastatic tissue compared with the primary tumor and against the background of targeted therapy. There was a decrease in the VHL expression in the metastases by 1.89 times and its content by 3.17 times compared with the primary tumor.
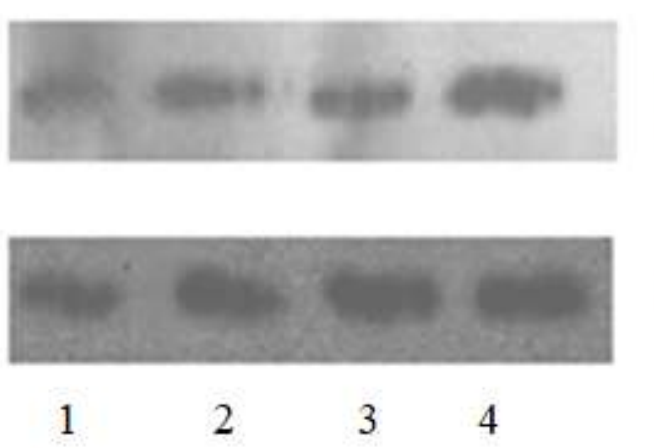

\section{pVHL, 25kDa}

\section{Actin, 29kDa}

4

Figure 1. p-VHL content in ccRCC tissues and adjacent non-transformed ones.

The expression and content of VHL depended on the stage of the disease (criterion T) and the extent of the tumor process in ccRCC (Table 3). The VHL 
expression was increased by 12.5 times in patients with a $\mathrm{T}_{3-4} \mathrm{~N}_{0-1} \mathrm{M}_{1}$ stage than $\mathrm{T}_{1-2} \mathrm{~N}_{0} \mathrm{M}_{0}$. The change was accompanied by a 5-fold decrease in the p-VHL in the patients with advanced cancers. The most significant changes were revealed when studying the prevalence of the tumor process. The expression and content of VHL are associated with the development of distant metastases. An increase in the VHL mRNA and its protein was recorded in patients with disseminated form by 32.0 and 2.68 times, respectively, of the disease, compared with patients with localized cancer.

Table 3. Expression and content of VHL in tumor tissue of patients depending on tumor size and disease spreading, $\mathrm{Me}(\mathrm{Q} 1 ; \mathrm{Q} 3)$

\begin{tabular}{|c|c|c|c|c|c|}
\hline \multirow{2}{*}{ Indicator } & \multicolumn{2}{|c|}{ Tumor size } & \multicolumn{3}{c|}{ Cancer dissemination } \\
\cline { 2 - 6 } & $\mathbf{T}_{1-2} \mathbf{N}_{0} \mathbf{M}_{0}$ & $\mathbf{T}_{3-4} \mathbf{N}_{\mathbf{0}-1} \mathbf{M}_{0-1}$ & Localized & \multicolumn{2}{c|}{ Metastatic } \\
cancer \\
\end{tabular}

Note: - * the significance of the differences with the localized form, $\mathrm{p}<0.05$; Note: ** the significance of the differences in comparison with the primary metastatic tumor, $\mathrm{p}<0.05$;

\subsection{BAP1, PBRM1, SETD2, PD-1, PD-L1, PD-L2 expression in ccRCC cancers.}

The BAP expression decreased with the tumor size growth and cancer spreading with distant metastases involvement (Table 4). A 7,26 decrease in mRNA level was found in primary disseminated cancers and metastatic tissues.

Table 4. BAP, SEDT1, PRBM expression in ccRCC tissues depending on tumor size and disease spreading, Me(Q1;

Q3)

\begin{tabular}{|c|c|c|c|c|c|c|}
\hline & \multicolumn{3}{|c|}{ Tumor size } & \multicolumn{3}{|c|}{ Cancer dissemination } \\
\hline Indicator & $\mathrm{T}_{1} \mathrm{~N}_{0} \mathrm{M}_{0}$ & $\mathrm{~T}_{2} \mathrm{~N}_{0} \mathrm{M}_{0-1}$ & $\mathrm{~T}_{3} \mathrm{~N}_{0} \mathrm{M}_{1}$ & $\begin{array}{l}\text { Localized } \\
\text { cancers }\end{array}$ & $\begin{array}{l}\text { Disseminated } \\
\text { cancers }\end{array}$ & Metastases \\
\hline \multirow[t]{2}{*}{ BAP } & $\begin{array}{l}2.27(1.57 ; \\
5.43)\end{array}$ & $\begin{array}{l}0.755 \quad(0.00 ; \\
1.77)\end{array}$ & $\begin{array}{l}0.50 \quad(0.00 ; \\
8.00)\end{array}$ & \multirow[t]{2}{*}{$\begin{array}{l}1.78 \quad(0.80 ; \\
4.64)\end{array}$} & \multirow[t]{2}{*}{$\begin{array}{l}0.245 \quad(0.00 \\
3.79)^{*}\end{array}$} & \multirow[t]{2}{*}{$\begin{array}{ll}0.255 & (0.005 \\
8.25)^{*} & \end{array}$} \\
\hline & \multicolumn{3}{|c|}{ Kruskal-Wallis test: $\mathrm{p}=\mathbf{0 . 0 4 8 5}$} & & & \\
\hline \multirow[t]{2}{*}{ SETD1 } & $\begin{array}{l}0.81(0.02 ; \\
24.87)\end{array}$ & $\begin{array}{ll}0.75 & (0.00 ; \\
2.00) & \end{array}$ & $\begin{array}{l}0.08 \quad(0.00 ; \\
22.65)\end{array}$ & \multirow[t]{2}{*}{$\begin{array}{l}0.905 \quad(0.04 ; \\
6.435)\end{array}$} & \multirow[t]{2}{*}{$0.34(0.00 ; 2.91)$} & \multirow[t]{2}{*}{$\begin{array}{l}0.265 \quad(0.015 ; \\
1.25)\end{array}$} \\
\hline & \multicolumn{3}{|c|}{ Kruskal-Wallis test: $\mathrm{p}=0.7687$} & & & \\
\hline \multirow[t]{2}{*}{ PRBM } & $\begin{array}{l}1.27(0.33 ; \\
8.00)\end{array}$ & $\begin{array}{l}1.0 \quad(0.23 ; \\
2.62)\end{array}$ & $\begin{array}{l}0.82 \quad(0.12 ; \\
32.00)\end{array}$ & \multirow[t]{2}{*}{$\begin{array}{l}1.72 \quad(0.385 ; \\
8.00)\end{array}$} & \multirow[t]{2}{*}{$0.66(0.10 ; 2.94)$} & \multirow[t]{2}{*}{$\begin{array}{ll}1.125 & (0.125 \\
2.60) & \end{array}$} \\
\hline & \multicolumn{3}{|c|}{ Kruskal-Wallis test: $\mathrm{p}=0.5417$} & & & \\
\hline
\end{tabular}

Note: - * the significance of the differences with the localized cancers, $\mathrm{p}<0.05$;

The study revealed a relationship between PD-1 and PD-L1 ligand expression, increasing tumor size (Table 5). The mRNA level of the PD receptor decreased 5.17 and 10.1 times in patients with tumor size in patients with stage T3N0M0 and T2N0M0 
compared with T1N0M0. There was also a decrease in the level of PD-L2 mRNA during tumor growth.

Table 5. PD, PD-L1, PD-L2 expression in ccRCC tissues depending on tumor size and disease spreading, Me(Q1;

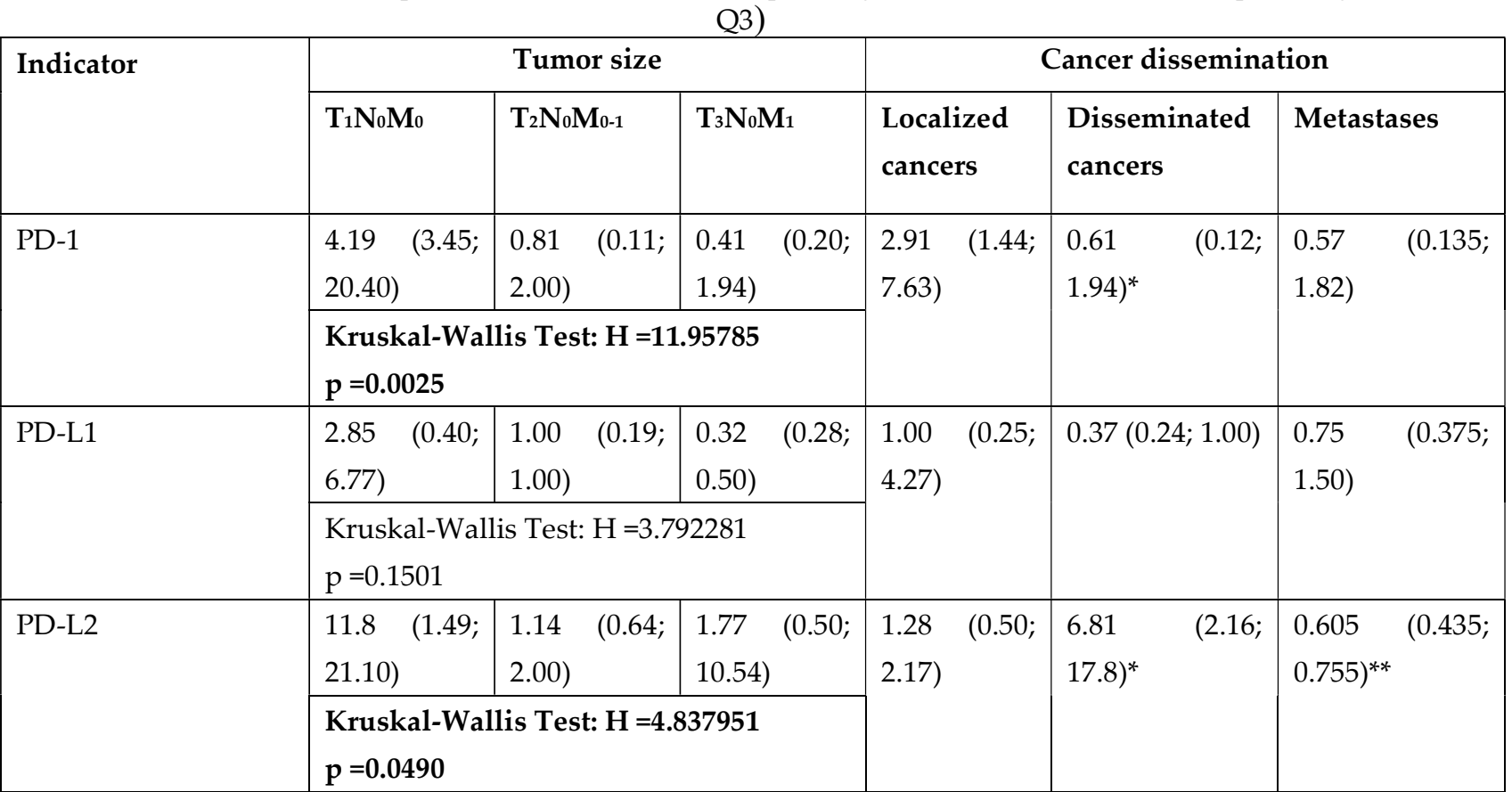

Note: * $^{*}$ the significance of the differences with the localized cancers, $\mathrm{p}<0.05$; ${ }^{* *}$ - the significance of the differences in comparison with the primary metastatic tumor, $\mathrm{p}<0.05$;

The presence of the disseminated form of the disease led to a decrease in PD expression by 4.75 times and an increase in PD-L2 expression by 5.3 times, respectively, compared with patients without distant metastases. A 2.69-fold decrease in the PD-L2 mRNA level in metastases was recorded compared to that in the primary tumor tissue.

\subsection{Correlation analysis.}

The presence of significant relationships between expression and protein content of von Hippel-Lindau was confirmed by correlation analysis. Thus, there was a correlation between the level of VHL expression and the corresponding protein content $(\mathrm{r}=$ $-0.46, \mathrm{p}=0.005$ ) (Figure 2). 


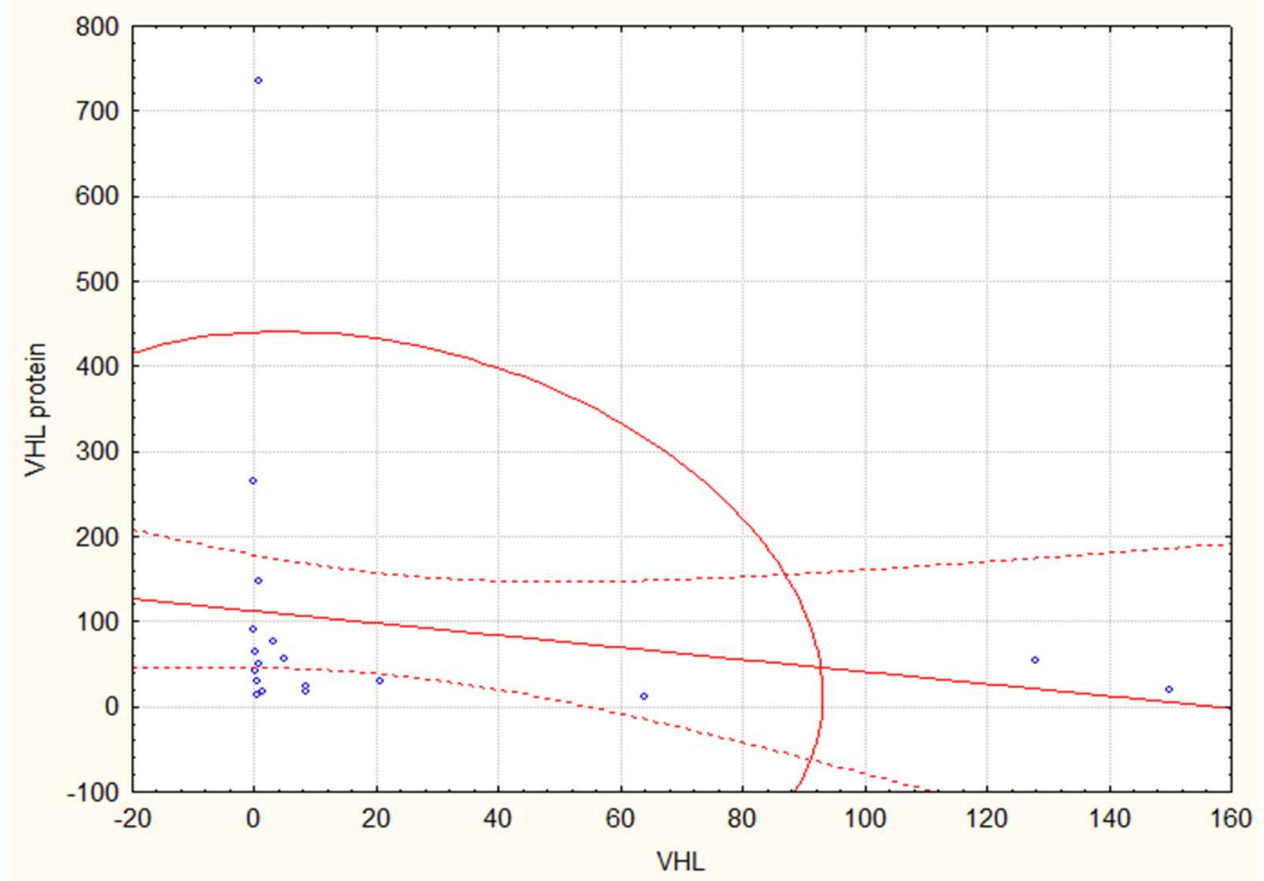

Figure 2. Scatter plots between VHL expression and p-VHL content.

But there are no correlations between the VHL and PD-1, PD-L1, PD-L2, and BAP1, PBRM1, SETD2 expression. The results revealed the direct connections between the immune markers and genes participating in chromatin remodeling and epigenetic regulation. Thus, BAP1 gene expression correlated with SEDT1 ( $r=0.28 ; \mathrm{p}<0.05)$, PRBM $(\mathrm{r}=0.50 ; \mathrm{p}<0.05)$, and PD-L2 $(\mathrm{r}=0.59 ; \mathrm{p}<0.05)$ expression. PD-L2 mRNA level associated with the PD-1 ( $r=0.30 ; p<0.05)$, PRBM $(r=0.27 ; p<0.05)$, SEDT1 $(r=0.34 ; p<0.05)$ expression. Finally, the SEDT1 mRNA level correlates with PRBM $(r=0.65 ; \mathrm{p}<0.05)$.

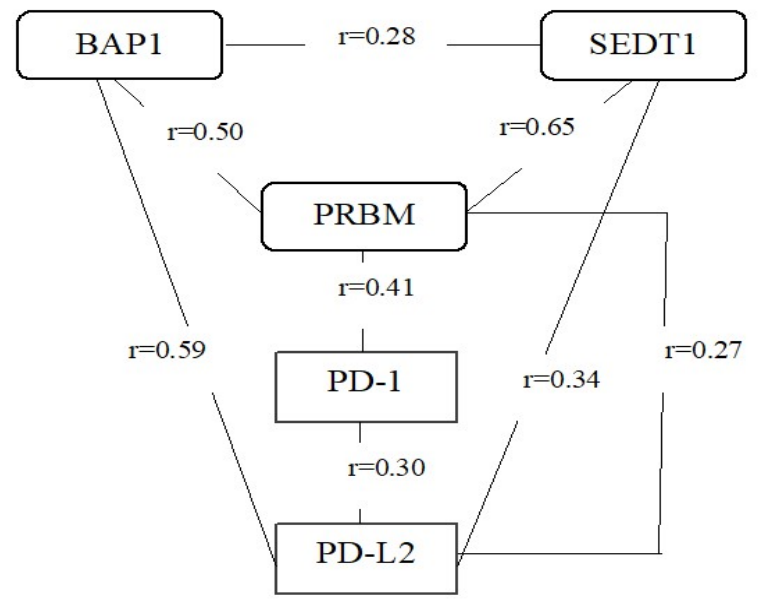

Figure 3. Associations between the PD-1, PD-L2, and BAP1, PBRM1, SETD2 expression in cCRCC.

Figure 3 shows the completed scheme of associations between the studied molecular markers. BAP1, PBRM1, SETD2 mRNA level correlated with the PD-L2 level. 
The data showed the presence of multiple regulatory triggers in PD-L2 activation and immune system regulation.

\section{Discussion}

ccRCC accounts for 2-3\% of all tumors, the most frequent solid lesion in the kidney. VHL influences the progression of ccRCC tumors. The higher expression of VHL was correlated with the better disease-free survival in ccRCC patients using The Cancer Genome Atlas (TCGA) datasets [14].

We found that an increase in VHL mRNA level with a p-VHL decrease in ccRCC was associated with increased tumor size. The prevalence of the disease was accompanied by an increase in both mRNA and VHL content. p-VHL and gene expression levels in the cancers are significantly reduced compared to the adjacent untransformed tissue and correlate with the disease stage, which is especially pronounced in metastatic ccRCC [3, 29-31].

Currently, about 32 significant mutations of the VHL gene and a large number of insignificant gene changes have been found. Lots of modifications [2]. The intensity of molecular processes in the oncogenesis of kidney cancer is associated with the role of protein in the regulation of essential cellular processes [5, 32-33]. These findings reveal a critical HIF-dependent molecular pathway connecting VHL, an established "gatekeeper" of the renal epithelium [32].

Renal cell carcinoma (RCC) includes diverse tumor types characterized by various genetic abnormalities. Genetic changes, like mutations, deletions, and epigenetic alterations, play a crucial role in modifying signaling networks, tumor pathogenesis, and prognosis. Loss of von Hippel-Lindau (VHL) gene and upregulation of hypoxiainducible factors (HIF), the signature of most sporadic ccRCC, promote multiple growth factors [4].

The presence of significant relationships between the expression and the content of the von Hippel-Lindau protein was confirmed by correlation analysis [34, 35]. An increase in the VHL mRNA level is associated with decreased related protein content and expression of the transcription factor NF- $\kappa \mathrm{B}$ p65. However, an increase in $\mathrm{p}-\mathrm{VHL}$ content in ccRCC tissues was associated with a decrease in the NF- $\kappa \mathrm{B}$ p65, NF- $\kappa \mathrm{B}$ p50, and VEGF expression. The presence of VHL mutations without taking into account the biological behavior of the tumor cannot determine the course, the outcome of the disease, and the effectiveness of targeted therapy [36]. The HIF overexpression associated with the p-VHL deficiency leads to cancer progression [7, 30-31, 37]. Significant changes in molecular factors also determine the development of disease metastases. In metastases, a decrease in the expression and content of p-VHL compared with the primary tumor was revealed, which was accompanied by an increase in the mRNA level of HIF-1, HIF-2, NF- $\kappa$ B p50, NF- $\kappa$ B p65, VEGF, and CAIX in the foci of secondary growth as compared with the primary tumor.

The hypoxia-induced transcription factor activation by VHL mutation is associated with $\mathrm{p}$-VHL protein loss. The VHL protein, promoting degradation of HIF $\alpha$, is involved in the modification of the transcriptional activity of the nuclear factor NF$\kappa \mathrm{B}$ [38]. The primary mechanism is direct hydroxylation of the NF- $\kappa \mathrm{B}$ factor and its repressor $\mathrm{I} \kappa \mathrm{B} \alpha[39]$. It is known that in the presence of the normal VHL protein, NF- $\mathrm{B}$ signaling is suppressed [38].

Although VHL mutations are triggers of ccRCC, the results demonstrated that genetic so on epigenetic factors impact the ccRCC invasive and metastatic properties due to VHL modifications. HIF-1 dependent protein CAIX is associated with increased aggressiveness [40]. The lncRNA FGD5-AS1 was significantly associated with VHL and can serve as a novel biomarker of ccRCC [41].

Recent genome-wide sequencing studies of ccRCC have revealed that mutations of genes coding for epigenome modifiers and chromatin remodelers, 
including PBRM1, SETD2, and BAP1, are the most common somatic genetic abnormalities after $V H L$ mutations in these tumors $[42,43]$.

Biological characteristics in tumor grade and aggressiveness across cancer types are well known poorly understood. BAP1- or SETD2-mutated ccRCCs have been associated with poor overall survival, while PBRM1 mutations seem to identify a favorable group of ccRCC tumors [9]. We detected the BAP expression in ccRCC is decreased with tumor size growth and metastasis development. BAP1 is crucial for kidney function and cooperates with VHL in renal oncogenesis [38]. Moreover, it is considered the driver of tumor grade, promoted by activation of mTORC1 [44].

The critical oncogenic event in ccRCC is VHL overexpression affecting the numerous processes. It results in inhibited epithelial-mesenchymal transition (EMT), sterol regulatory element-binding protein 1 regulated triglyceride synthesis, and cell proliferation [14]. VHL overexpression led to upregulation of proteins associated with antigen processing and interferon-responsive proteins, rendering ccRCC cells with high VHL expression more sensitive to interferon treatment. The data indicate that the subset of ccRCC patients with high VHL expression benefit from immunotherapy [14]. Recent studies showed that PD-L1 expression levels positively correlate with VHL mutation and HIF- $2 \alpha$ expression. VHL mutations positively correlate with PD-L1 expression in ccRCC and may influence the response to cCRCC anti-PD-L1/PD-1 immunotherapy [15].

The significance of immune system regulation has been verified in correlation analysis. The prevalence and distribution of PD-L2 are found to be correlated significantly with PD-L1 [16]. The PD-L2 level is found to be dependent on the BAP1, PBRM1, SETD2 expression. Previous studies have shown a relationship between the PD-L1 expression with a ccRCC poor prognosis [16-18]. The study revealed high levels of PD-L2 mRNA in patients with metastatic ccRCC. PD-L2 expression was observed in all tumor types and present in the stroma, tumor, and endothelial cells. However, PDL2 was detected in the absence of PD-L1 in some tumor types [13]. The low rates in PD1, PD-1, and PD-L2 were found in the tissue of metastases. The revealed data substantiate the contribution of heterogeneity and biological characteristics to the progression of the disease [22].

An increase in tumor immunogenicity during tumor progression is the foremost progression step associated with VHL inactivation [19, 20, 23-24, 28]. Previous studies have revealed a relationship between VHL expression and components of the AKT/mTOR signaling cascade and transcriptional and growth factors [35], which possibly determines the response to targeted therapy. In addition, the activation of the AKT mTOR signaling pathway and an increase in gene expression and the content of transcriptional and growth factors have been shown [30-31] in ccRCC.

\section{Materials and Methods}

A total of 62 patients with RCC were enrolled in the study. The retrospective study included patients with histopathologically verified RCC admitted to and nephrectomized at the Cancer Research Institute, Tomsk National Research Center, Russian Academy of Medical Sciences, Tomsk, Russian Federation. The patients underwent a physical examination, chest radiography, and computer tomography (CT) of the abdomen. When vena cava tumor thrombus invasion was suspected, cavography or magnetic resonance imaging (MRI) was performed. Patients with skeletal-associated pain or elevated serum alkaline phosphatase were assessed with bone scintigraphy. The patients were followed up according to a program, including regular clinical and radiological examinations. The median age of the patients was 57 years. The RCC therapy depends on the tumor size and its spreading to other parts of the body.

Localized RCC (T1-3N0M0) was diagnosed in 18 patients, metastatic RCC (T2$4 \mathrm{~N} 0-1 \mathrm{M} 1$ ) in 44 patients. All patients with localized RCC underwent surgery (partial 
nephrectomy or simple nephrectomy) and then followed up according to a program including regular clinical and radiological examinations. Patients with metastatic RCC received two cycles of preoperative targeted therapy with pazopanib at a dose of 800 mg daily for two months. Tumor response to targeted therapy was evaluated according to RECIST criteria. All patients underwent radical nephrectomy. The diagnosis was verified based on biopsy results.

The Local Committee approved the study for Medical Ethics, and all patients provided written informed consent (protocol code 4; 16.11.2018). Tumor tissue samples, histologically normal tissue samples adjacent to tumors, and metastatic tissues were used for investigation. Specimens were reviewed separately by two independent pathologists.

RNA extraction. The postoperative tumor samples were incubated in RNAlater solution (Ambion, USA) for 24 -hours at $+4{ }^{\circ} \mathrm{C}$ and then stored at $-80 \mathrm{oC}$. Total RNA was extracted using the RNeasy Mini Kit (Qiagen).

RT-qPCR. PCR was conducted in $25 \mu \mathrm{l}$ reaction volumes containing $12.5 \mu \mathrm{l}$ BioMaster HS-qPCR SYBR Blue (2X) ("Biolabmix" Russia) and 300 nanoM of each primers. .VHL: F 5' - GGCAGGCGAATCTCTTGA-3” , R 5'-CTATTTCCTTTACTCAGCACCATT-3'; BAP1: F 5' - GCCACGGACAGCAGAGAG-3', R 5'-CTTCCTCTTCTCTACCTCCTCCT-3'; PRBM1 : F 5' - CCCAGTAGCCTTGTCGCA-3', R 5'-TAGTCAATAAGAGCAGAGTTCAATCA-3'; SEDT1: F 5' - CAGAGTTATGCCCAGCCAA-3', R 5'GAGTTCCCAGGTCCATCTCA-3'; PD-L2: F 5'-GTTCCACATACCTCAAGTCCAA-3', R 5'-ATAGCACTGTTCACTTCCCTCTT-3'; PD-L1: F 5'-AGGGAGAATGATGGATGTGAA-3', R 5'-ATCATTCACAACCACACTCACAT-3'; PD-1-1: F 5'-CTGGGCGGTGCTACAACT-3', R 5'-CTTCTGCCCTTCTCTCTGTCA-3'; GAPDH: F 5' - GGAAGTCAGGTGGAGCGA-3' , R 5'-GCAACAATATCCACTTTACCAGA-3' . At $95^{\circ} \mathrm{C}$ for $10 \mathrm{~min}$, a pre-incubation was to activate the Hot Start DNA polymerase and denature DNA and was followed by 45 amplification cycles of $95^{\circ} \mathrm{C}$ denaturations at 95 0 for $10 \mathrm{sec}, 60^{\circ} \mathrm{C}$ annealings at 600 for $20 \mathrm{sec}$ (iCycler iQ ${ }^{\mathrm{TM}}$, BioRad).

The fold changes were calculated by $\Delta \Delta \mathrm{Ct}$ method (the total $\Delta \Delta \mathrm{Ct}=$ fold of cancerous/normal tissue gene level), using normal tissue. A ratio of specific mRNA/ GADPH (GADPH as a respective control) amplification was then calculated.

Determination of $p$-VHL level in tissues. Electrophoresis SDS-PAGE (Laemmli) was used. The protein was transferred to a 0.2-/xm pore-sized PVDF membrane (GE Healthcare, UK), either at $150 \mathrm{~mA}$ or $100 \mathrm{~V}$ for one $\mathrm{h}$ by using a Bio-Rad Mini TransBlot electrophoresis cell. The membrane was incubated in a 1:2500 dilution of monoclonal mouse anti-p-VHL (Ser68) (Affinity Biosciences, USA) at four ${ }^{\circ} \mathrm{C}$ overnight.

PVDF samples were incubated in Amersham ECL western blotting detection analysis system (Amersham, USA). The results were standardized using the beta-actin expression in a sample and were expressed in percentages to the protein content in non-transformed tissues. The analysis of the results was carried out using the ChemiDocTMTouch Imaging System, and their density was assessed using the ImageLab computer program (BioRad, USA). The level of protein in normal non-altered tissue was indicated as $100 \%$.

Statistical analysis. Statistical analysis was performed using SPSS 19.0 software. Data were expressed as median and ranges. Mann-Whitney test was used for comparing differences in mean values. Nonparametric one-way ANOVA on ranks was carried out to test whether samples originate from the same distribution, which is used to compare two or more independent samples of equal or different sample sizes. Nonparametric correlation analysis was performed, and the Spearmen coefficient was calculated. The significance of differences in the frequencies of qualitative traits was evaluated using the $\chi 2$ criterion with the Yates correction. 


\section{Conclusions}

The von Hippel-Lindau gene product acts as the substrate-recognition component of an E3 ubiquitin ligase complex that ubiquitylates the catalytic alpha subunit of the hypoxia-inducible factor for oxygen-dependent destruction. VHL abnormalities and alterations guide in ccRCC oncogenesis. We found the prevalence of VHL expression in increased tumor growth and metastases development. The VHL expression and pVHL content determine the aggressive cancer behavior and are elevated in disseminated tumors. ccRCC progression in VHL overexpression is associated with the decrease in BAP1 gene expression. The prevalence of PD-L2, PD-1 ligand, is found in metastatic cancers. It should be considered as an independent factor of cancer aggressiveness.

It is revealed the heterogeneity in molecular markers in primary tumors and metastases. We found the low mRNA level of BAP1, PBRM1, SETD2, PD-1, PD-L1, PD-L2 in ccRCC metastases compared with primary tumors. Direct and indirect relationships in molecular factors determine the biological behavior and therapeutic effect. There are opposite data on the VHL expression in ccRCC and its significance in cancer development. This work shows a novel mechanism for VHL tumor progression and presents a new instrument and factor for targeting tumor-related pathologies with $\mathrm{p}$-VHL/HIF altered function. The relationship between the expression and content of the VHL protein is of decisive importance in ccRCC oncogenesis. This new insight in ccRCC progression may offer prominent opportunities for therapeutic intervention

\section{Supplementary Materials: No}

Author Contributions: Conceptualization, Liudmila Spirina. and Zahar Yrmazov; methodology, Evgeny Usynin; formal analysis, Ekaterine Ladutko; investigation, Liudmila Spirina; resources, Evgeny Choynzonov.; data curation, Zahar Yurmazov.; writing-original draft preparation, Spirina L.V..; writing - review and editing, Spirina L.V. All authors have read and agreed to the published version of the manuscript."

Funding: This research received no external funding

Institutional Review Board Statement: The study was conducted according to the guidelines of the Declaration of Helsinki, and approved by the Institutional Review Board (or Ethics Committee) (protocol code 4; 16.11.2018).

Informed Consent Statement: Written informed consent has been obtained from the patient(s) to publish this paper.

Acknowledgments: No

Conflicts of Interest: The authors declare no conflict of interest.

\section{Appendix A}

Not acceptable

\section{Appendix B}

Figure 1. Note: 1, 3-cancers, 2,4-non-transformed tissues; $\mathrm{p}$-VHL content is a key oncogenic event in ccRCC development. It promotes and triggers the main biological processes resulting in modification of metabolism, immune regulation, apoptosis, and cell movement.

Figure 2. Note: VHL expression and p-VHL content are the decisive points on oncogenesis governing kidney cancer spreading and disease progression. VHL/HIF/VEGF pathway and VHL/PD-1/PD-L1/PD-L2 axis determine the ccRCC aggressive behavior. 
Figure 3. Note: The roles of PBRM1, BAP1, and SETD2 in the development and progression of ccRCC and their potential for future personalized approaches are connected with immune system regulation. PD-L2 level is a potential target

\section{References}

1. Gossage, L.; Murtaza, M.; Slatter, A.F.; Lichtenstein, C.P.; Warren, A.; Haynes, B.; Marass, F.; Roberts, I.; Shanahan, S.J.; Claas, A.; Dunham, A; May, A.P.; Rosenfeld, N.; Forshew, T.; Eisen, T. Clinical and pathological impact of VHL, PBRM1, BAP1, SETD2, KDM6A, and JARID1c in clear cell renal cell carcinoma. Genes Chromosomes Cancer 2014, 53(1), 38-51. DOI: $10.1002 /$ gcc.22116.

2. Alves, M.R.; Carneiro, F.C.; Lavorato-Rocha, A.M.; da Costa, W.H.; da Cunha, I.W.; de Cássio Zequi, S.; Guimaraes, G.C.; Soares, F.A.; Carraro, D.M.; Rocha, R.M. Mutational status of VHL gene and its clinical importance in renal clear cell carcinoma. Virchows Arch 2014, 465(3), 321-30. DOI: 10.1007/s00428-014-1629-z.

3. Ferchichi, I.; Kourda, N.; Sassi, S.; Romdhane, K.B.; Balatgi, S.; Cremet, J.Y.; Prigent, C.; Elgaaied, A.B.; Aurora-A overexpression and pVHL reduced expression are correlated with a bad kidney cancer prognosis. Dis Markers 2012, 33(6), 333-40. DOI: 10.3233/DMA-2012-00942.

4. Tumkur Sitaram, R.; Landström, M.; Roos, G.; Ljungberg, B. Significance of PI3K signalling pathway in clear cell renal cell carcinoma in relation to VHL and HIF status. J Clin Pathol 2021, 74(4), 216-222. DOI: 10.1136/jclinpath-2020-206693.

5. Arias-González, L.; Moreno-Gimeno, I.; del Campo, A.R.; Serrano-Oviedo, L.; Valero, M.L.; Esparís-Ogando, A.; de la CruzMorcillo, M.Á.; Melgar-Rojas, P.; García-Cano, J.; Cimas, F.J.; Hidalgo, M.J.; Prado, A.; Callejas-Valera, J.L.; Nam-Cha, S.H.; Giménez-Bachs, J.M.; Salinas-Sánchez, A.S.; Pandiella, A.; del Peso, L.; Sánchez-Prieto, R. ERK5/BMK1 is a novel target of the tumor suppressor VHL: implication in clear cell renal carcinoma. Neoplasia 2013, 15(6), 649-59. DOI: 10.1593/neo.121896.

6. Nyhan, M.J.; El Mashad, S.M.; O'Donovan, T.R.; Ahmad, S.; Collins, C.; Sweeney, P; Rogers, E.; O'Sullivan, G.C.; McKenna, S.L. VHL genetic alteration in CCRCC does not determine de-regulation of HIF, CAIX, hnRNP A2/B1 and osteopontin. Cell Oncol (Dordr) 2011, 34(3), 225-34. DOI: 10.1007/s13402-011-0029-5.

7. Choueiri, T.K.; Fay, A.P.; Gagnon, R.; Lin, Y.; Bahamon, B.; Brown, V.; Rosenberg, J.E.; Hutson, T.E.; Baker-Neblett, K.L.; Carpenter, C.; Liu, Y.; Pandit, L.; Signoretti, S. The role of aberrant VHL/HIF pathway elements in predicting clinical outcome to pazopanib therapy in patients with metastatic clear-cell renal cell carcinoma. Clin Cancer Res 2013, 19(18), 5218-26. DOI: 10.1158/1078-0432.CCR-13-0491.

8. Wang, S.S.; Gu, Y.F.; Wolff, N.; Stefanius, K.; Christie, A.; Dey, A.; Hammer, R.E.; Xie, X.J.; Rakheja, D.; Pedrosa, I.; Carroll, T.; McKay, R.M.; Kapur, P.; Brugarolas, J. Bap1 is essential for kidney function and cooperates with Vhl in renal tumorigenesis. Proc Natl Acad Sci U S A 2014, 111(46), 16538-43. DOI: 10.1073/pnas.1414789111.

9. Piva, F.; Santoni, M.; Maturana, M.R.; Satti, S.; Giulietti, M.; Occhipinti, G.; Massari, F.; Cheng, L.; Lopez-Beltran, A.; Scarpelli, M.; Principato, G.; Cascina, S.; Montironi, R. BAP1, PBRM1 and SETD2 in clear-cell renal cell carcinoma: molecular diagnostics and possible targets for personalized therapies. Expert Rev Mol Diagn 2015, 15(9), 1201-10. DOI: 10.1586/14737159.2015.1068122.

10. Moreira, M.; Pobel, C.; Epaillard, N.; Simonaggio, A.; Oudard, S.; Vano, Y.A. Resistance to cancer immunotherapy in metastatic renal cell carcinoma. Cancer Drug Resist 2020, 3, 454-471. DOI: 10.20517/cdr.2020.16

11. Bihr, S.; Ohashi, R.; Moore, A.L.; Rüschoff, J.H.; Beisel, C.; Hermanns, T.; Mischo, A.; Corrò, C.; Beyer, J.; Beerenwinkel, N.; Moch, H.; Schraml, P. Expression and Mutation Patterns of PBRM1, BAP1 and SETD2 Mirror Specific Evolutionary Subtypes in Clear Cell Renal Cell Carcinoma. Neoplasia 2019, 21(2), 247-256. DOI: 10.1016/j.neo.2018.12.006.

12. Kushlinskii, N.E.; Fridman, M.V.; Morozov, A.A.; Gershtei, E.S.; Kadagidze, Z.G.; Matveev, V.B. Modern approaches to kidney cancer immunotherapy. Cancer Urology 2018, 14(2), 54-67. DOI: 10.17650/1726-9776-2018-14-2-54-67.

13. Yearley, J.H.; Gibson, C.; Yu, N.; Moon, C.; Murphy, E.; Juco, J.; Lunceford, J.; Cheng, J.; Chow, L.Q.M.; Seiwert, T.Y.; Handa, M.; Tomassini, J.E.; McClanahan, T. PD-L2 Expression in Human Tumors: Relevance to Anti-PD-1 Therapy in Cancer. Clin Cancer Res 2017, 23(12), 3158-3167. DOI: 10.1158/1078-0432.CCR-16-1761.

14. Zhu, S.; Ding, W.; Chen, Y.; Wang, W.; Xu, R.; Liu, C.; Liu, X.; Deng, H.; High, V.H.L. Expression Reverses Warburg Phenotype and Enhances Immunogenicity in Kidney Tumor Cells. Genomics Proteomics Bioinformatics 2021, S1672-0229(21), 000395. DOI: 10.1016/j.gpb.2019.12.002.

15. Messai, Y.; Gad, S.; Noman, M.Z.; Le Teuff, G.; Couve, S.; Janji, B.; Kammerer, S.F.; Rioux-Leclerc, N.; Hasmim, M.; Ferlicot, S.; Baud, V.; Mejean, A.; Mole, D.R.; Richard, S.; Eggermont, A.M.; Albiges, L.; Mami-Chouaib, F.; Escudier, B.; Chouaib, S. Renal Cell Carcinoma Programmed Death-ligand 1, a New Direct Target of Hypoxia-inducible Factor-2 Alpha, is Regulated by von Hippel-Lindau Gene Mutation Status. Eur Urol 2016, 70(4), 623-632. DOI: 10.1016/j.eururo.2015.11.029.

16. Hong, B.; Cai, L.; Wang, J.; Liu, S.; Zhou, J.; Ma, K.; Zhang, J.; Zhou, B.; Peng, X.; Zhang, N.; Gong, K. Differential Expression of PD-L1 Between Sporadic and VHL-Associated Hereditary Clear-Cell Renal Cell Carcinoma and Its Correlation With Clinicopathological Features. Clin Genitourin Cancer. 2019, 17(2), 97-104.el. DOI: 10.1016/j.clgc.2018.11.001.

17. Kammerer-Jacquet, S.F.; Crouzet, L.; Brunot, A.; Dagher, J.; Pladys, A.; Edeline, J.; Laguerre, B.; Peyronnet, B.; Mathieu, R.; Verhoest, G.; Patard, J.J.; Lespagnol, A.; Mosser, J.; Denis, M.; Messai, Y.; Gad-Lapiteau, S.; Chouaib, S.; Belaud-Rotureau, M.A.; Bensalah, K.; Rioux-Leclercq, N. Independent association of PD-L1 expression with noninactivated VHL clear cell renal cell carcinoma-A finding with therapeutic potential. Int J Cancer 2017, 140(1), 142-148. DOI: 10.1002/ijc.30429. 
18. Lu, Y.; Song, Y.; Xu, Y.; Ou, N.; Liang, Z.; Hu, R.; Zhang, W.; Kang, J.; Wang, X.; Liu, L.; Yang, Y.; Liu, X. The prevalence and prognostic and clinicopathological value of PD-L1 and PD-L2 in renal cell carcinoma patients: a systematic review and metaanalysis involving 3,389 patients. Transl Androl Urol 2020, 9(2), 367-381. DOI: 10.21037/tau.2020.01.21.

19. Ueda, K.; Suekane, S.; Kurose, H.; Chikui, K.; Nakiri, M.; Nishihara, K.; Matsuo, M.; Kawahara, A.; Yano, H.; Igawa, T. Prognostic value of PD-1 and PD-L1 expression in patients with metastatic clear cell renal cell carcinoma. Urol Oncol 2018, 36(11), 499.e9-499.e16. DOI: 10.1016/j.urolonc.2018.07.003.

20. Tanegashima, T.; Togashi, Y.; Azuma, K.; Kawahara, A.; Ideguchi, K.; Sugiyama, D.; Kinoshita, F.; Akiba, J.; Kashiwagi, E.; Takeuchi, A.; Irie, T.; Tatsumi, K.; Hoshino, T.; Eto, M.; Nishikawa, H. Immune Suppression by PD-L2 against Spontaneous and Treatment-Related Antitumor Immunity. Clin Cancer Res 2019, 25(15), 4808-4819. DOI: 10.1158/1078-0432.CCR-18-3991.

21. Philips, E.A.; Garcia-España, A.; Tocheva, A.S.; Ahearn, I.M.; Adam, K.R.; Pan, R.; Mor, A.; Kong, X.P. The structural features that distinguish PD-L2 from PD-L1 emerged in placental mammals. J Biol Chem 2020, 295(14), 4372-4380. DOI: 10.1074/jbc.AC119.011747.

22. Zhang, X.; Yin, X.; Zhang, H.; Sun, G.; Yang, Y.; Chen, J.; Zhu, X.; Zhao, P.; Zhao, J.; Liu, J.; Chen, N.; Wang, J.; Shen, P.; Zeng, H. Differential expressions of PD-1, PD-L1 and PD-L2 between primary and metastatic sites in renal cell carcinoma. BMC Cancer 2019, 19(1), 360. DOI: 10.1186/s12885-019-5578-4.

23. Lastwika, K.J.; Wilson, W. 3rd.; Li, Q.K.; Norris, J.; Xu, H.; Ghazarian, S.R.; Kitagawa, H.; Kawabata, S.; Taube, J.M.; Yao, S.; Liu, L.N.; Gills, J.J.; Dennis, P.A. Control of PD-L1 Expression by Oncogenic Activation of the AKT-mTOR Pathway in NonSmall Cell Lung Cancer. Cancer Res 2016, 76(2), 227-38. DOI: 10.1158/0008-5472.CAN-14-3362.

24. Tsai, T.F.; Lin, J.F.; Lin, Y.C.; Chou, K.Y.; Chen, H.E.; Ho, C.Y.; Chen, P.C.; Hwang, T.I. Cisplatin contributes to programmed death-ligand 1 expression in bladder cancer through ERK1/2-AP-1 signaling pathway. Biosci Rep 2019, 39(9), BSR20190362. DOI: 10.1042/BSR20190362.

25. Dong, L.; Lv, H.; Li, W.; Song, Z.; Li, L.; Zhou, S; Qiu, L.; Qian, Z.; Liu, X.; Feng, L.; Meng, B.; Fu, K.; Wang, X.; Pan-Hammarström, Q.; Wang, P.; Wang, X.; Zhang, H. Co-expression of PD-L1 and p-AKT is associated with poor prognosis in diffuse large B-cell lymphoma via PD-1/PD-L1 axis activating intracellular AKT/mTOR pathway in tumor cells. Oncotarget 2016, 7(22), 33350-62. DOI: 10.18632/oncotarget.9061.

26. Noman, M.Z.; Desantis, G.; Janji, B.; Hasmim, M.; Karray, S.; Dessen, P.; Bronte, V.; Chouaib, S. PD-L1 is a novel direct target of HIF-1 $\alpha$, and its blockade under hypoxia enhanced MDSC-mediated T cell activation. J Exp Med 2014, 211(5), 781-90. DOI: 10.1084/jem.20131916.

27. Ruf, M.; Moch, H.; Schraml, P. PD-L1 expression is regulated by hypoxia-inducible factor in clear cell renal cell carcinoma. Int J Cancer 2016, 139(2), 396-403. DOI: 10.1002/ijc.30077.

28. Tatli Dogan, H.; Kiran, M.; Bilgin, B.; Kiliçarslan, A.; Sender, M.A.N.; Yalçin, B.; Ardiçoglu, A.; Atmaca, A.F.; Gumuskaya, B. Prognostic significance of the programmed death-ligand 1 expression in clear cell renal cell carcinoma and correlation with the tumor microenvironment and hypoxia-inducible factor expression. Diagn Pathol 2018, 13(1), 60. DOI: 10.1186/s13000-018-0742-8.

29. Xiao-Fen, W; Ting, C; Jie, L; Deng-Yang, M; Qing-Feng, Z, Xin, L. Correlation analysis of VHL and Jade-1 gene expression in human renal cell carcinoma. Open Med (Wars) 2016, 11(1), 226-230. DOI: 10.1515/med-2016-0043.

30. Spirina, L.V.; Yurmazov, Z.A.; Gorbunov, A.K.; Usynin, E.A.; Lushnikova, N.A.; Kovaleva, I.V. Molecular Protein and Expression Profile in the Primary Tumors of Clear Cell Renal Carcinoma and Metastases. Cells 2020, 9(7), 1680. DOI: 10.3390/cells9071680.

31. Spirina, L.V.; Kondakova, I.V.; Yurmazov, Z.A.; Usynin, E.A.; Slonimskaya, E.M.; Lushnikova, N.A.; Podnebesnova, D.V. VHL Expression in Kidney Cancer: Relation to Metastasis Development, Transcription and Growth Factors and Component of Akt/m-TOR Signaling Pathway. Bull Exp Biol Med 2019, 167(5), 671-675. DOI: 10.1007/s10517-019-04596-9.

32. Evans, A.J.; Russell, R.C.; Roche, O.; Burry, T.N.; Fish, J.E.; Chow, V.W.; Kim, W.Y.; Saravanan, A.; Maynard, M.A.; Gervais, M.L.; Sufan, R.I.; Roberts, A.M.; Wilson, L.A.; Betten, M.; Vandewalle, C.; Berx, G.; Marsden, P.A.; Irwin, M.S.; The, B.T.; Jewett, M.A.; Ohh, M. VHL promotes E2 box-dependent E-cadherin transcription by HIF-mediated regulation of SIP1 and snail. Mol Cell Biol 2007, 27(1), 157-69. DOI: 10.1128/MCB.00892-06.

33. Mikhaylova, O.; Stratton, Y.; Hall, D.; Kellner, E.; Ehmer, B.; Drew, A.F.; Gallo, C.A.; Plas, D.R.; Biesiada, J.; Meller, J.; Czyzyk-Krzeska, M.F. VHL-regulated MiR-204 suppresses tumor growth through inhibition of LC3B-mediated autophagy in renal clear cell carcinoma. Cancer Cell 2012, 21(4), 532-46. DOI: 10.1016/j.ccr.2012.02.019.

34. Spirina, L.V.; Usynin, E.A.; Yurmazov, Z.A.; Slonimskaya, E.M.; Kondakova, I.V. Effect of Targeted Therapy With Pazopanib on Expression Levels of Transcription, Growth Factors and Components of AKT/m-TOR Signaling Pathway in Patients with Renal Cell Carcinoma. Asian Pac J Cancer Prev. 2017, 18(11), 2977-2983. DOI: 10.22034/APJCP.2017.18.11.2977.

35. Spirina, LV, Kondakova, IV, Yurmazov, ZA, Usynin, EA, Slonimskaya EM, Lushnikova, NA, Podnebesnova, DV. VHL Expression in Kidney Cancer: Relation to Metastasis Development, Transcription and Growth Factors and Component of Akt/m-TOR Signaling Pathway. Bull Exp Biol Med. 2019, 167(5), :671-675. doi: 10.1007/s10517-019-04596-9.

36. Kim, B.J; Kim, J.H; Kim, H.S; Zang, D.Y. Prognostic and predictive value of VHL gene alteration in renal cell carcinoma: a meta-analysis and review. Oncotarget 2017, 8(8), 13979-13985. DOI: 10.18632/oncotarget.14704.

37. Less, F.; Mazzanti, C.M.; Tomei, S.; Di Cristofano, C.; Minervini, A.; Menicagli, M.; Apollo, A.; Masieri, L.; Collecchi, P.; Minervini, R.; Carini, M.; Bevilacqua, G. VHL and HIF-1 $\alpha$ : gene variations and prognosis in early-stage clear cell renal cell carcinoma. Med Oncol 2014, 31(3), 840. DOI: 10.1007/s12032-014-0840-8. 
38. Wang, J.; Ma, Y.; Jiang, H.; Zhu, H.; Liu, L.; Sun, B.; Pan, S.; Kristiansen, G.W.; Sun, X. Overexpression of von Hippel-Lindau protein synergizes with doxorubicin to suppress hepatocellular carcinoma in mice. J Hepatol 2011, 55(2), 359-68. DOI: 10.1016/j.jhep.2010.10.043.

39. Walmsley, S.R.; McGovern, N.N.; Whyte, M.K.; Chilvers, E.R. The HIF/VHL pathway: from oxygen sensing to innate immunity. Am J Respir Cell Mol Biol 2008, 38(3), 251-5. DOI: 10.1165/rcmb.2007-0331TR.

40. Diez-Calzadilla, N.A.; Noguera Salvá, R.; Soriano Sarrió, P.; Martínez-Jabaloyas, J.M. Genetic profile and immunohistochemical study of clear cell renal carcinoma: Pathological-anatomical correlation and prognosis. Cancer Treat Res Commun 2021, 27, 100374. DOI: 10.1016/j.ctarc.2021.100374.

41. Yang, H.; Minamishima, Y.A.; Yan, Q.; Schlisio, S.; Ebert, B.L.; Zhang, X.; Zhang, L.; Kim, W.Y.; Olumi, A.F.; Kaelin, W.G. Jr. pVHL acts as an adaptor to promote the inhibitory phosphorylation of the NF-kappaB agonist Card9 by CK2. Mol Cell 2007, 28(1), 15-27. DOI: 10.1016/j.molcel.2007.09.010.

42. Mehdi, A.; Riazalhosseini, Y. Epigenome Aberrations: Emerging Driving Factors of the Clear Cell Renal Cell Carcinoma. Int J Mol Sci 2017, 18(8), 1774. DOI: 10.3390/ijms18081774.

43. Gao, W.; Li, W.; Xiao, T.; Liu, XS.; Kaelin, W.G. Jr. Inactivation of the PBRM1 tumor suppressor gene amplifies the HIFresponse in VHL-/- clear cell renal carcinoma. Proc Natl Acad Sci U S A 2017, 114(5), 1027-1032. doi: 10.1073/pnas.1619726114.

44. Gu, Y.F.; Cohn, S.; Christie, A.; McKenzie, T.; Wolff, N.; Do, Q.N.; Madhuranthakam, A.J.; Pedrosa, I.; Wang, T.; Dey, A.; Busslinger, M.; Xie, X.J.; Hammer, R.E.; McKay, R.M.; Kapur, P.; Brugarolas, J. Modeling Renal Cell Carcinoma in Mice: Bap1 and Pbrm1 Inactivation Drive Tumor Grade. Cancer Discov 2017, 7(8), 900-917. DOI: 10.1158/2159-8290.CD-170292. 